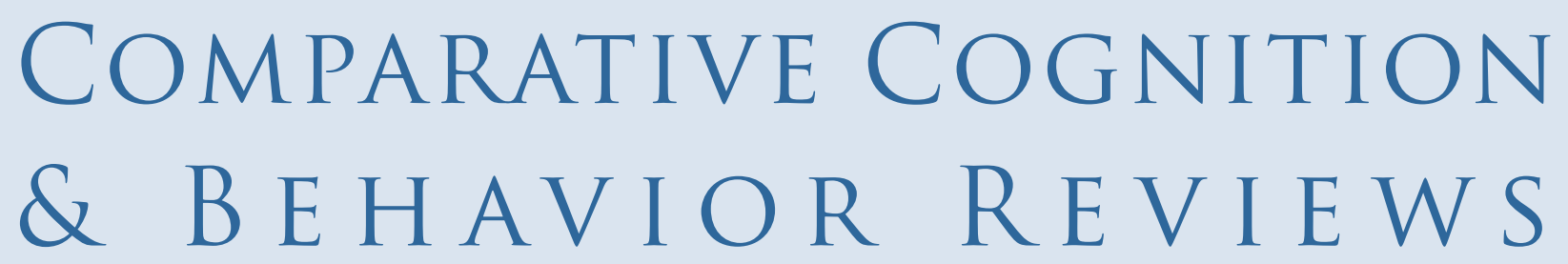

\title{
Evolved Psychological Mechanisms as Constraints on Optimization
}

\author{
Marco Vasconcelos \\ Department of Education and Psychology \\ and William James Center for Research \\ University of Aveiro
}

\author{
Valeria V. González and Alejandro Macías \\ School of Psychology \\ University of Minho
}

Behavior and its underpinning mechanisms are the product of evolution by natural selection just as many other biological traits. This does not imply that all behavior should be optimal. The biological optimization agent is natural selection, not the behaving organism. Behavior may or may not be close to optimal depending on the degree to which the current circumstances match the organism's typical ecology. Evolved mechanisms impose constraints, and situations generating suboptimal preferences are singular opportunities to study the particulars of such mechanisms.

\section{Keywords: constraint, heuristic, mechanism, suboptimal choice}

Behavior and its underpinning mechanisms are products of the same evolutionary process that lead to eyes, thumbs, or insect wings. Through natural selection, heritable traits that best promote reproduction and survival increase their frequency across generations, ultimately leading to evolutionary change. In the long term, such traits appear as if they had been designed to maximize inclusive fitness. Just as wings appear designed to enhance flight efficiency, so too do known psychological mechanisms appear designed to optimize the net return of behavioral allocation.

Driven by naive interpretations of this premise, researchers often conclude that most (if not all) behavior should be flexible and perfectly adaptable to the environmental demands. Because behavior and its supporting mechanisms were sculpted by the optimizing action of natural selection, it is frequently assumed that behavior itself must be optimal. This conclusion erroneously moves the biological optimization agent to the current, real-time behaving agent when in fact natural selection acted in the past - current behavioral patterns are those that outperformed other variants across generations. They are presently adaptive only if the circumstances still reflect the chief statistical properties of the environments that shaped them. Consequently, behavior may be close to optimal in the environment that an animal is likely to encounter in its typical ecology but suboptimal when the current environment does not mirror the main features of the environment where it evolved. It all comes to the match between the domain of selection and the domain of testing (Houston, McNamara, \& Steer, 2007; Stevens \& Stephens, 2010).

Thus, animals are not expected to behave optimally in every circumstance. On average, the available behavioral processes must perform well across a range of different circumstances; otherwise they would be selected against. But they also can and do lead to suboptimal behavior when the situation deviates from 
the species' typical ecological demands (Fawcett et al., 2014; McNamara \& Houston, 2009). In fact, the catalogue of "irrational" or suboptimal behaviors identified in both human and nonhuman animals has been growing steadily in recent decades (e.g., Bateson, Healy, \& Hurly, 2002; Doyle, O'Connor, Reynolds, \& Bottomley, 1999; Gigerenzer, Hertwig, \& Pachur, 2011; Goldstein \& Gigerenzer, 2002; Kalenscher, Tobler, Huijbers, Daselaar, \& Pennartz, 2010; Shafir, 1994; Shafir, Waite, $\&$ Smith, 2002; Waite, 2001). These deviations are interesting not because they question normative approaches (which they do not) but because they expose specific situations where evolved mechanisms backfire. They are opportunities to identify such mechanisms, understand their nuts and bolts, and perhaps begin to grasp their adaptive significance.

The Zentall lab has been a prolific contributor to this literature through inventive and persistent experimentation (e.g., Zentall, 2010, 2011, 2013, 2014; Zentall, 2016a, 2016b; Zentall, Case, \& Luong, 2016). In his latest contribution, Zentall (2019) tours another set of indisputably suboptimal choice behavior. He shows how several animal species repeatedly prefer one over two pieces of food (the less-is-better effect); how they prefer one piece of food delivered immediately over two pieces of the same food, one now and the second delayed (the ephemeral choice task); and how animals commit errors of anticipation and perseveration even when reliable cues are available to guide their behavior (the midsession reversal task). After asking what evolved mechanisms could account for such deviations, Zentall concludes that "suboptimal behavior can be explained in terms of evolved heuristics that work reasonably well in nature but sometimes fail under laboratory conditions" (p. 13).

The term heuristic carries a theoretical meaning in the behavioral sciences. Although Zentall (2019) does not specify the boundaries within which he uses the term, we argue that heuristics understood as shortcuts to find quick and efficient (optimal or not) solutions pose problems to the entire enterprise. The search for such heuristics implements a sort of behavioral gambit (Fawcett, Hamblin, \& Giraldeau, 2013) that, even though reminiscent of the phenotypic gambit, is probably not granted.

Author Note: Marco Vasconcelos, Department of Education and Psychology, University of Aveiro, Campus Universitário de Santiago, 3810-193 Aveiro, Portugal.

Correspondence concerning this article should be addressed to MarcoVasconcelos at mvasconcelos@ua.pt
Whereas the phenotypic gambit assumes that the genetic makeup does not constrain the evolution of phenotypes (Grafen, 1984) and is regarded as a suitable approximation in the long term, this variation of the behavioral gambit assumes that existing psychological mechanisms do not constrain the emergence of bespoke rules for each problem. In our view, this assumption is misguided particularly for flexible behaviors that change within an individual's lifetime.

The notion that agents may follow simple rules capable of producing either optimal or sufficiently good solutions has been explored in several disciplines. Whereas in human cognitive psychology these rules are known as heuristics (e.g., Gigerenzer \& Goldstein, 1996; Gigerenzer et al., 2011), in behavioral ecology they are usually referred to as rules of thumb (e.g., Davies, Krebs, \& West, 2012). The common assumption seems to be that natural selection will endow organisms with specific solutions to the problems that organisms face repeatedly across generations. Considering the demands that animals face within and across generations, this approach implies the existence of both an extensive collection of such rules and an overseeing mechanism to select the rule to use in each situation (Kacelnik, 2012; Vasconcelos, Fortes, \& Kacelnik, 2017). For instance, in the less-is-better effect (preference for one desirable piece of food over the same food plus a less desirable item), Zentall (2019) proposed an averaging heuristic of the two possible outcomes, which reduces the value of the alternative with more food, yet under which circumstances this heuristic would be advantageous and how this heuristic is selected among others remain unclear. In addition, the approach seems to neglect well-known and general psychological mechanisms such as those emanating from learning theory, favoring the search for innovative yet narrow-domain algorithms.

We argue instead that natural environments are so complex and dynamic that the best natural selection can do, particularly when behaviors vary within each life span, is to furbish an animal with a set of generalpurpose, broad-domain mechanisms. We favor the search for general mechanisms that perform well, on the average, in a variety of problems rather the search for a collection of complex rules (i.e., heuristics) that perform well on a very circumscribed set of problems (cf. McNamara \& Houston, 2009).

The search for mechanisms should go hand in hand with functional queries. It is when they are considered jointly that we understand how functional issues constrain which mechanisms evolve and how existing 
mechanisms restrict the set of available solutions to a problem. Thus, when faced with seemingly paradoxical preferences, one should ask how the puzzling results could originate from known mechanisms possibly operating under circumstances different from those that helped shape their current form and function. In other words, we replace heuristics by learning processes independently known. Such a theoretical exercise should then be followed by extensive testing of the assumptions made and, one hopes, of novel predictions derived from them (Vasconcelos, Machado, \& Pandeirada, 2018). Obviously, when needed, known processes should be supplemented by new proposals. Within-trial contrast, for instance, illustrates well how new proposals are sometimes needed to buttress known mechanisms (cf. Zentall, 2010).

To conclude, independently known learning mechanisms are the product of evolution by natural selection just as many other biological traits. They can be conceived as possible adaptations, but they also impose constraints on optimization. Once this dual nature of learning mechanisms is recognized, suboptimal preferences can be used as tools to understand them, not as tools to dispel them.

\section{References}

Bateson, M., Healy, S. D., \& Hurly, T. A. (2002). Irrational choices in hummingbird foraging behaviour. Animal Behaviour, 63, 587-596. doi:10.1006/anbe.2001.1925

Davies, N. B., Krebs, J. R., \& West, S. A. (2012). An introduction to behavioural ecology (4th ed.). Hoboken, NJ: Wiley-Blackwell.

Doyle, J. R., O’Connor, D. J., Reynolds, G. M., \& Bottomley, P. A. (1999). The robustness of the asymmetrically dominated effect: Buying frames, phantom alternatives, and in-store purchases. Psychology and Marketing, 16, 225-243. doi:10.1002/(SICI)1520-6793(199905)16:3<225:: AID-MAR3 $>3$.0.CO;2-X

Fawcett, T. W., Fallenstein, B., Higginson, A. D., Houston, A. I., Mallpress, D. E. W., Trimmer, P. C., \& McNamara, J. M. (2014). The evolution of decision rules in complex environments. Trends in Cognitive Sciences, 18, 153-161. doi:10.1016/j.tics.2013.12.012
Fawcett, T. W., Hamblin, S., \& Giraldeau, L. A. (2013). Exposing the behavioral gambit: The evolution of learning and decision rules. Behavioral Ecology, 24, 2-11. doi:10.1093/beheco/ars085

Gigerenzer, G., \& Goldstein, D. G. (1996). Reasoning the fast and frugal way: models of bounded rationality. Psychological Review, 103, 650-669. doi:10.1037/0033-295X.103.4.650

Gigerenzer, G., Hertwig, R., \& Pachur, T. (2011). Heuristics: The foundations of adaptive behavior. Oxford, UK: Oxford University Press. doi:10.1093/acprof:oso/9780199744282.001.0001

Goldstein, D. G., \& Gigerenzer, G. (2002). Models of ecological rationality: The recognition heuristic. Psychological Review, 109, 75-90. doi:10.1037/0033-295x.109.1.75

Grafen, A. (1984). Natural selection, kin selection and group selection. In J. R. Krebs \& N. B. Davies (Eds.), Behavioural ecology: An evolutionary approach (2nd ed., pp. 62-84). Oxford, England: Blackwell Scientific.

Houston, A. I., McNamara, J. M., \& Steer, M. D. (2007). Do we expect natural selection to produce rational behaviour? Philosophical Transactions of the Royal Society B: Biological Sciences, 362, 15311543. doi:10.1098/rstb.2007.2051

Kacelnik, A. (2012). Putting mechanisms into behavioral ecology. In P. Hammerstein \& J. R. Stevens (Eds.), Evolution and the mechanisms of decision making (pp. 21-38). Cambridge, MA: MIT Press.

Kalenscher, T., Tobler, P. N., Huijbers, W., Daselaar, S. M., \& Pennartz, C. M. A. (2010). Neural signatures of intransitive preferences. Frontiers in Human Neuroscience, 4, 49. doi:10.3389/fnhum.2010.00049

McNamara, J. M., \& Houston, A. I. (2009). Integrating function and mechanism. Trends in Ecology and Evolution, 24, 670-675. doi:10.1016/j.tree.2009.05.011 
Shafir, S. (1994). Intransitivity of preferences in honey bees: Support for 'comparative' evaluation of foraging options. Animal Behaviour, 48, 55-67. doi:10.1006/anbe.1994.1211

Shafir, S., Waite, T. A., \& Smith, B. H. (2002). Context-dependent violations of rational choice in honeybees (Apis mellifera) and gray jays (Perisoreus canadensis). Behavioral Ecology and Sociobiology, 51, 180-187. doi:10.1007/s00265-001-0420-8

Stevens, J. R., \& Stephens, D. W. (2010). The adaptive nature of impulsivity. In G. J. Madden \& W. K. Bickel (Eds.), Impulsivity: The behavioral and neurological science of discounting (pp. 361-387). Washington, DC: American Psychological Association. doi:10.1037/12069-013

Vasconcelos, M., Fortes, I., \& Kacelnik, A. (2017). On the structure and role of optimality models in the study of behavior. In J. Call (Ed.), APA handbook of comparative psychology (Vol. 2, pp. 287-307). Washington, DC: American Psychological Association. doi:10.1037/0000012-014

Vasconcelos, M., Machado, A., \& Pandeirada, J. N. S. (2018). Ultimate explanations and suboptimal choice. Behavioural Processes, 152, 63-72. doi:10.1016/j.beproc.2018.03.023

Waite, T. A. (2001). Intransitive preferences in hoarding gray jays (Perisoreus canadensis). Behavioral Ecology and Sociobiology, 50, 116-121. doi:10.1007/s002650100346

Zentall, T. R. (2010). Justification of effort by humans and pigeons: Cognitive dissonance or contrast? Current Directions in Psychological Science, 19, 296-300. doi:10.1177/0963721410383381
Zentall, T. R. (2011). Maladaptive "gambling" by pigeons. Behavioural Processes, 87, 50-56. doi:10.1016/j.beproc.2010.12.017

Zentall, T. R. (2013). Animals prefer reinforcement that follows greater effort: Justification of effort or within-trial contrast? Comparative Cognition \& Behavior Reviews, 8, 60-77. doi:10.3819/ccbr.2013.80004

Zentall, T. R. (2014). Suboptimal choice by pigeons: An analog of human gambling behavior. Behavioural Processes, 103, 156-164. doi:10.1016/j.beproc.2013.11.004

Zentall, T. R. (2016a). Resolving the paradox of suboptimal choice. Journal of Experimental Psychology: Animal Learning and Cognition, 42, 1-14. doi:10.1037/xan0000085

Zentall, T. R. (2016b). When humans and other animals behave irrationally. Comparative Cognition \& Behavior Reviews, 11, 25-48. doi:10.3819/ccbr.2016.110002

Zentall, T. R. (2019). What suboptimal choice tells us about the control of behavior. Comparative Cognition \& Behavior Reviews, 14, 1-17. doi:10.3819/CCBR.2019.140001

Zentall, T. R., Case, J. P., \& Luong, J. (2016). Pigeon's (Columba livia) paradoxical preference for the suboptimal alternative in a complex foraging task. Journal of Comparative Psychology, 130, 138-144. doi:10.1037/com0000026 